\title{
Speed Control for Four Quadrant Operation of Three Phase Bldc Motor Using Digital Controller
}

\author{
Aswathy Paul \\ Student Mtech Power Electronics (EEE Department) Toch Institute of science \& Technology \\ Arakunnam,Kerala,India
}

\begin{abstract}
This paper proposes a method that estimates rotor position by using an unknown input observer over a full speed range. In this method, a trapezoidal back emf is modeled as an unknown input and the proposed unknown input observer estimating line to line back emf in real time makes it possible to detect the rotor position. This observer has high performance even at low speed range because rotor position is calculated independently of the rotor speed without adding any additional circuit or complicated operation process. Simulations have been carried out for the verification of proposed control scheme. MAT LAB/SIMULINK model is used for software simulation.
\end{abstract}

Keywords-BLDC motor, Four quadrant operation, sensorless control, full speed range, unknown input observer.

\section{Introduction}

The bldc motor employs an electronic commutator and the motor's reliability and efficiency are improved by eliminating this source of wear and power loss. BLDC motors offers a number of advantages over brushed dc motors and induction motors including noiseless operation; higher speed ranges; better speed versus torque characteristics and faster dynamic response. The BLDC motor is known as synchronous motor because the magnetic field generated by stator and rotor revolve at the same frequency and the benefit of this arrangement is that the bldc motor does not experience slip like that of induction motors. The Hall Effect sensors which are used for rotor position estimation will increase the cost and size of the motor. The Hall Effect sensors are temperature sensitive, limiting the operation of the motor to below about $75^{\circ} \mathrm{C}$ and could reduce the system reliability because of the components and wiring. Therefore sensorless control of BLDC motor has been becoming more popular in recent years due to advantages like cost reduction, reliability improvement, elimination of difficulty in maintaining sensors etc. The sensorless method of control is highly advantageous if the motor is operating in dusty or oily environment where occasional cleaning of Hall Effect sensor is required for proper sensing of rotor position. In the motors rated below one watt rating the power consumption by position sensors can substantially reduce the motor efficiency. As a result sensorless drives that can control position, speed and torque without shaft mounted position sensors has been used[3,4].

Conventional sensorless control method can be divided into four categories. First, the open phase current sensing method[5] which is used for detecting the conducting interval of freewheeling diode connected in antiparallel with power transistors. This method has the advantage that synchronous process is simple and the control characteristic has high performance at low speeds. However rotor position resolution conspicuously decreases at high speeds and for realization of this method, it has the defect that additional isolated power needs to supply to a comparator for detecting the freewheeling current. Secondly, the method detecting the third harmonic of back emf $[6,7]$ is a technique to remove all the fundamental and other polyphase components through a simple summation of three phase voltages. The neutral point that is not considered in the manufacturing process of motor is needed to measure phase voltages and the third harmonic detection is difficult at low speed range. Thirdly, the back emf integrating method[8,9] which is a technique applying the principle that integration is constant from zero crossing point to $30^{\circ}$. This method has the drawback that it does not synchronize the phase current with back emf at the sensorless drive. Finally the open phase voltage sensing method [10-13] is a technique for estimating the rotor position indirectly by using the zero crossing point detection of open phase's terminal voltage. This method has a deteriorated response at transient state.

To solve the above problems, this paper proposes a new sensorless control method using an unknown input observer that is independent of the rotor speed for a brushless dc motor drive and can effectively estimate a line to line back emf.

\section{Modelling Of Bldc Motor}

The analysis of brushless dc motor is based on the following assumptions:

- BLDC motor is not saturated 
- Stator resistances are equal

- Self and mutual inductances are constant

- Semiconductor devices of inverter are ideal

- Iron losses are negligible

- Back emf waveforms of all phases are equal

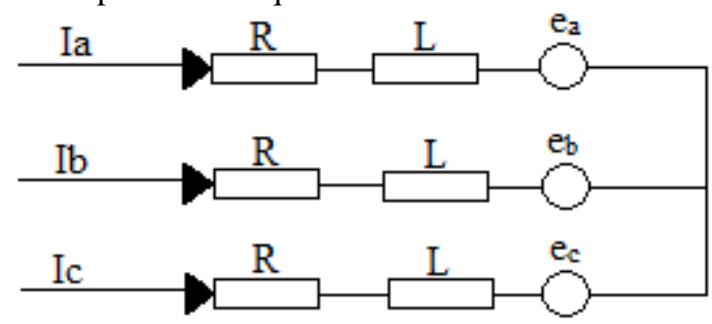

Fig 1 Equivalent circuit of BLDC motor

The dynamic equations of BLDC motors under the above assumptions are derived based on the equivalent circuit of BLDC motor.

$\left[\begin{array}{l}V a \\ V b \\ V c\end{array}\right]=\left[\begin{array}{ccc}R & 0 & 0 \\ 0 & R & 0 \\ 0 & 0 & R\end{array}\right]\left[\begin{array}{c}i a \\ i b \\ i c\end{array}\right]+\left[\begin{array}{ccc}L & M & M \\ M & L & M \\ M & M & L\end{array}\right] \mathrm{d} / \mathrm{dt}\left[\begin{array}{c}i a \\ i b \\ i c\end{array}\right]+\left[\begin{array}{c}e a \\ e b \\ e c\end{array}\right]$

$\mathrm{ia}+\mathrm{ib}+\mathrm{ic}=0$

Mia+Mib+Mic $=0$

Therefore,

$\left[\begin{array}{l}V a \\ V b \\ V c\end{array}\right]=\left[\begin{array}{ccc}R & 0 & 0 \\ 0 & R & 0 \\ 0 & 0 & R\end{array}\right]\left[\begin{array}{c}i a \\ i b \\ i c\end{array}\right]+\left[\begin{array}{ccc}L-M & 0 & 0 \\ 0 & L-M & 0 \\ 0 & 0 & L-M\end{array}\right] \mathrm{d} / \mathrm{dt}\left[\begin{array}{l}i a \\ i b \\ i c\end{array}\right]+\left[\begin{array}{l}e a \\ e b \\ e c\end{array}\right]$

The trapezoidal back emfs are modeled as a function of rotor position as:

$\mathrm{e}_{\mathrm{a}}=\mathrm{K}_{\mathrm{e}} \mathrm{W}_{\mathrm{m}} \mathrm{F}_{\mathrm{a}}\left(\theta_{\mathrm{e}}\right)$

$\mathrm{e}_{\mathrm{b}}=\mathrm{K}_{\mathrm{e}} \mathrm{W}_{\mathrm{m}} \mathrm{F}_{\mathrm{b}}\left({ }_{\mathrm{e}^{-}}-\frac{2 \pi}{3}\right)$

$\mathrm{e}_{\mathrm{c}}=\mathrm{K}_{\mathrm{e}} \mathrm{W}_{\mathrm{m}} \mathrm{F}_{\mathrm{c}}\left(\theta_{\mathrm{e}}+\frac{2 \pi}{3}\right)$

$\mathrm{T}_{\mathrm{a}}=\mathrm{K}_{\mathrm{t}} \mathrm{i}_{\mathrm{a}} \mathrm{F}_{\mathrm{a}}\left({ }_{\mathrm{e}}\right)$

$\mathrm{T}_{\mathrm{b}}=\mathrm{K}_{\mathrm{t}} \mathrm{i}_{\mathrm{b}} \mathrm{F}_{\mathrm{b}}\left(\theta_{\mathrm{e}^{-}} \frac{2 \pi}{3}\right)$

$\mathrm{T}_{\mathrm{c}}=\mathrm{K}_{\mathrm{t}} \mathrm{i}_{\mathrm{c}} \mathrm{F}_{\mathrm{c}}\left(\theta_{\mathrm{e}}+\frac{2 \pi}{3}\right)$

$\mathrm{T}_{\mathrm{e}}=\mathrm{T}_{\mathrm{a}}+\mathrm{T}_{\mathrm{b}}+\mathrm{T}_{\mathrm{c}}$

The electromagnetic torque can be expressed as:

$\mathrm{T}_{\mathrm{e}}=\mathrm{J} \frac{d^{2} \theta}{d t^{2}}+\mathrm{B} \frac{d \theta_{m}}{d t}+\mathrm{T}_{1}$

${ }_{\mathrm{e}}=\mathrm{P} / 2{ }_{\mathrm{m}}{ }_{\mathrm{m}}$;

$\mathrm{W}_{\mathrm{m}}=\frac{d \theta_{m}}{d t}$

$\mathrm{T}_{\mathrm{e}}=1 / \mathrm{W}_{\mathrm{m}}\left(\mathrm{e}_{\mathrm{a}} \mathrm{i}_{\mathrm{a}}+\mathrm{e}_{\mathrm{b}} \mathrm{i}_{\mathrm{b}}+\mathrm{e}_{\mathrm{c}} \mathrm{i}_{\mathrm{c}}\right)$

Where

$\mathrm{J}$ is the moment of inertia;

$\mathrm{B}$ is the frictional coefficient;

$\mathrm{W}_{\mathrm{m}}$ is the angular velocity of the motor;

$\mathrm{T}_{1}$ is the load torque

$\mathrm{T}_{\mathrm{k}}$ is the electric torque produced by $\mathrm{k}^{\text {th }}$ phase $(\mathrm{k}=\mathrm{a}, \mathrm{b}, \mathrm{c})$

$\mathrm{T}_{\mathrm{e}}$ is the electric torque produced by BLDC 
$\mathrm{K}_{\mathrm{e}}$ is the back emf constant

$\mathrm{K}_{\mathrm{t}}$ is the torque constant

$\mathrm{W}_{\mathrm{m}}$ is the angular speed of rotor

${ }_{\mathrm{m}}$ is the mechanical angle of rotor

$\theta_{\mathrm{e}}$ is the electrical angle of rotor

$\mathrm{F}\left({ }_{\mathrm{e}}\right)$ is the back emf reference as function of rotor position

$$
\mathrm{F}_{\mathrm{a}}\left(\theta_{\mathrm{e}}\right)=\left\{\begin{array}{cc}
(6 / \pi) \theta & (0 \angle \theta \leq \pi / 6) \\
1 & (\pi / 6 \angle \theta \leq 5 \pi / 6) \\
-(6 / \pi) \theta+6 & (5 \pi / 6 \angle \theta \leq 7 \pi / 6) \\
-1 & (7 \pi / 6 \angle \theta \leq 11 \pi / 6) \\
(6 / \pi) \theta+12 & (11 \pi / 6 \angle \theta \leq 2 \pi)
\end{array}\right.
$$

$\mathrm{F}_{\mathrm{b}}\left({ }_{\mathrm{e}}{ }_{\mathrm{e}}\right)$ and $\mathrm{F}_{\mathrm{c}}\left({ }_{\mathrm{e}}\right)$ are $120^{\circ}$ and $240^{\circ}$ phase shifted with respect to $\mathrm{F}_{\mathrm{a}}\left({ }_{\mathrm{e}}\right)$.

\section{Four Quadrant Operation}

There are four possible quadrants of operation using a brushless DC motor which is shown in figure 2. When the brushless DC motor is operating in the first and third quadrant, the supplied voltage is greater than back emf which is known as forward motoring and reverse motoring modes respectively, but the direction of current flow differs. When the motor is operating in the second and fourth quadrant, the back emf generated by motor should be greater than supplied voltage which is forward motoring and reverse motoring modes respectively and here again the direction of current flow is reversed.

The motor is initially made to rotate in the clockwise direction and when the speed reversal command is obtained, the control goes into clockwise regeneration mode which brings the rotor to standstill position. Instead of waiting for exact standstill position, continuous energization of main phase is attempted and this rapidly slows down the rotor of the machine to standstill position. Therefore there is the necessity of determining the instant when the rotor is ideally positioned for reversal. Hall Effect sensors are used to obtain the rotor position and from the hall sensor outputs it is determined whether the machine has reversed its direction which is the ideal moment for energizing the stator phase so that machine can start motoring in the counter clockwise direction.

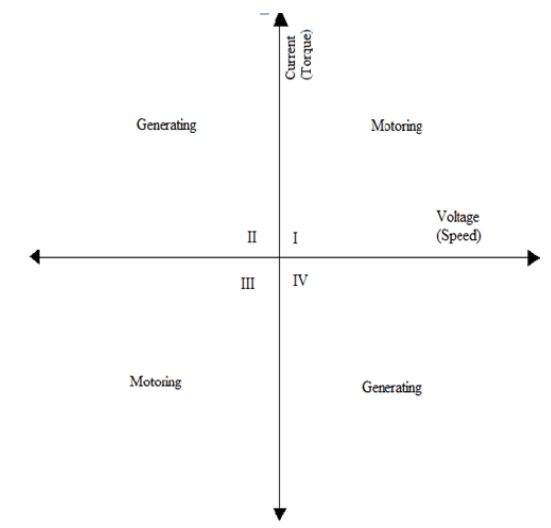

Figure 2 Four quadrants of operation

\section{Proposed System}

A new sensorless control method is proposed using an unknown input observer that is independent of the rotor speed for a brushless dc motor drive and can effectively estimate a line to line back emf. Sensorless control methods such as back emf detection method show high performance only at high speed because magnitude of back emf is dependent upon rotor speed. In the proposed system rotor position is estimated by using an unknown input observer over a full speed range. A trapezoidal back emf is modeled as an unknown input. The unknown input observer estimating line to line back emf in real time makes it possible to detect the rotor position. This observer has high performance even at low speed because the rotor position is calculated independently of rotor speed without an additional circuit or complicated operation process.

In the proposed sensorless control method, rotor position can be detected by using trapezoidal back emf of BLDC motors. Since the back emf of brushless DC motor is not measured directly, it is measured by using an unknown input observer which is constructed by a back emf regarded as an unknown input and the state of the 
BLDC motor drive system. The proposed method can determine the motor position within $60^{\circ}$ motor revolutions and detects the commutation instance by using commutation functions which are based on the estimated line to line back emfs with $60^{\circ}$ resolutions. After detecting the first commutation point, speed and torque can be controlled with a sensorless algorithm with the estimated speed calculated by time interval of commutation points.

Whenever there is a reversal of direction of rotation it implies there will be a change in the quadrant. When the motor is operating in the motoring mode in the clockwise direction, the relay contacts get opened. When braking is applied or when the speed reversal commands are obtained, the relay contacts get closed. The kinetic energy which will be wasted as heat energy is now converted into electrical energy which is rectified and stored in a rechargeable battery. The braking energy is return back to the power source which increases the complexity of the circuit; the DC power generated has to be inverted to be returned back to the mains.

The frequent reversal in the direction of rotation will result in the continuous charging of battery. When interruption of power supply occurs, the energy stored in the battery can be used to run the same motor. The actual speed of the motor is fed back to dsPIC controller and is compared with the reference speed. The difference in speed generates an error signal and aids the motor to run at constant speed. When brake is applied, the speed reduces to zero.

Figure 3 shows the overall structure of proposed sensorless drive system. The line to line voltage is calculated according to the dc link voltage and switching status of the inverter. The back emf observer provides the estimated line to line back emf. The commutation function, speed and rotor position are calculated using estimated line to line back emfs. The commutation signal generation block generates commutation signals according to calculated rotor position and commutation function.

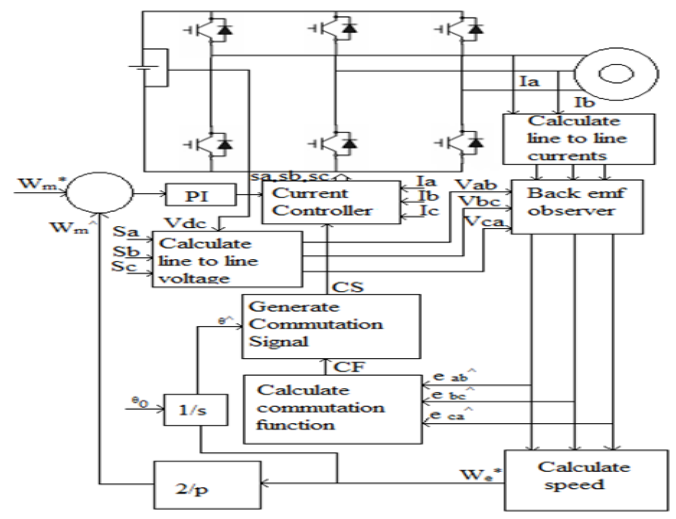

Figure 3 Overall Structure of the Proposed Sensorless Drive System

\section{A. COMMUTATION FUNCTION}

The sensorless control method which decides the commutation instances of switching devices by detecting the zero crossing point of back emf has been commonly used. But this method cannot detect zero crossing point at low speed range. To solve this problem, sensitive commutation function defined by using line to line back emf is proposed to improve the performance of sensorless control scheme and the commutation functions are defined as:

Mode 1 and 4: $\mathrm{CF}\left({ }^{\theta}\right)_{1}=\mathrm{e}_{\mathrm{bc}}{ }^{\wedge} / \mathrm{e}_{\mathrm{ca}} \hat{}$

Mode 2 and 5: $\operatorname{CF}\left({ }^{\theta}\right)_{2}=\mathrm{e}_{\mathrm{ab}} \wedge / \mathrm{e}_{\mathrm{bc}} \wedge$

Mode 3 and 6: $\mathrm{CF}\left({ }^{\theta}\right)_{3}=\mathrm{e}_{\mathrm{ca}} / \mathrm{e}_{\mathrm{ab}}$

\section{B. ESTIMATION OF SPEED AND POSITION}

If the estimated magnitude of a back emf is defined, the speed and rotor position can be calculated. The relationship between speed and back emf in BLDC motor is:

$\mathrm{E}=\mathrm{K}_{\mathrm{e}} \mathrm{W}_{\mathrm{e}}$

Where

$\mathrm{E}$ is the magnitude of back emf;

$\mathrm{K}_{\mathrm{e}}$ is the back emf constant

$\mathrm{W}_{\mathrm{e}}$ is the angular velocity

The magnitude of back emf is estimated by the maximum magnitude of the line to line back emf that the unknown input observer gives. Therefore speed can be calculated by using estimated magnitude of back emf as: $\mathrm{W}_{\mathrm{e}}^{\wedge}=\mathrm{E}^{\wedge} / \mathrm{K}_{\mathrm{e}}$

$\mathrm{W}_{\mathrm{m}} \hat{\imath}=2 / \mathrm{P} \mathrm{W}_{\mathrm{e}}$;

where 
$\mathrm{W}_{\mathrm{m}}{ }^{\wedge}$ is the estimated mechanical angular velocity

$\mathrm{P}$ is the number of poles

The rotor position is obtained by integrating the speed of the motor:

$\theta^{\wedge}=\int \mathrm{W}_{\mathrm{e}}{ }^{\wedge} \mathrm{dt}+{ }_{0}$

Where

${ }_{0}^{\theta}$ is the initial rotor position.

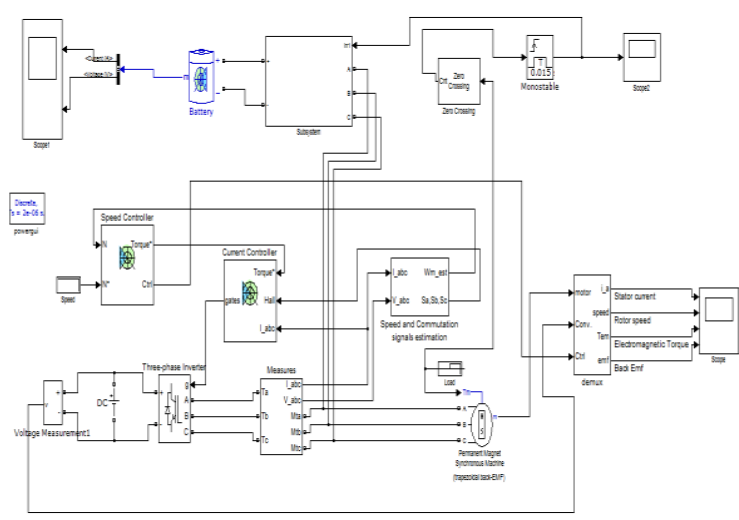

Figure 4 Simulink model of proposed system

\section{Simulation Results}

The closed loop controller for three phase BLDC motor is modeled using MATLAB/ Simulink. Permanent magnet synchronous machine with trapezoidal back emf is modeled as BLDC motor. Figure 4 shows the Simulink model of the proposed system. In the proposed system, motor speed and position are estimated from terminal voltages and currents using back emf observer. In every 60 electrical degrees, commutation signals equivalent to Hall Effect signals are generated from rotor position. The permanent magnet synchronous machine with trapezoidal back emf is fed by a PWM voltage source inverter which is built using a universal bridge block. The speed control loop uses a PI controller to produce torque reference for current control block. The current control blocks computes three reference motor line currents in phase with the back emfs, corresponding to torque reference and then feeds the motor with these currents using a three phase current regulator.

The speed regulation is accomplished with PI controller. The controller's sensitivity is increased by increasing the proportional gain of the controller thereby faster reaction for small speed regulation errors.

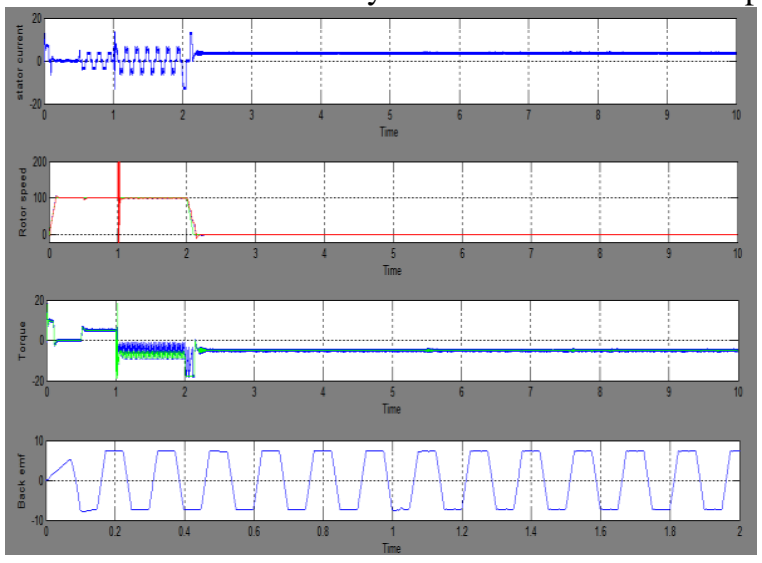

Figure 5 Waveforms of stator current, rotor speed, electromagnetic torque and back emf

Figure 5 shows the waveforms of stator current, rotor speed, electromagnetic torque and back emf. At time $t=0$ $\mathrm{sec}$, the speed set point is $400 \mathrm{rpm}$ and can observe that speed increases to $400 \mathrm{rpm}$ precisely following the acceleration ramp. At $\mathrm{t}=0.5 \mathrm{sec}$, full load torque is applied to motor and can observe a small disturbance in motor speed which stabilizes very quickly. At $\mathrm{t}=1 \mathrm{sec}$, the speed set point is changed to $0 \mathrm{rpm}$ and can observe that speed decreases down to $0 \mathrm{rpm}$ precisely following the deceleration ramp.

\section{Conclusion}

A new approach to sensorless control of BLDC motor drives using an unknown input observer is proposed. In this method, a trapezoidal back emf is modeled as an unknown input and the unknown input 
observer estimating line to line back emf in real time makes it possible to detect the rotor position. This observer has high performance at a low speed range because rotor position is calculated independently of the rotor speed without an additional circuit or complicated operation process.

The sensorless control method using an unknown input observer can

- Be achieved without any additional circuits

- Estimate rotor speed in real time for precise control

- Make commutation pulse even in transient state as well as in steady state

- Detect the rotor position effectively over a full speed range

\section{References}

[1] C. Sheeba Joice, S. R. Paranjothi, and V. Jawahar Senthil Kumar, "Digital Control Strategy for Four Quadrant Operation of Three Phase BLDC Motor With Load Variations,", IEEE Transactions On Industrial Informatics, Vol. 9, No. 2, May 2013.

[2] Tae-Sung Kim, Byoung-Gun Park, Dong-Myung Lee, Ji-Su Ryu, and Dong-Seok Hyun, “ A New Approach to Sensorless Control Method for Brushless DC Motors”, International Journal of Control, Automation, and Systems, vol. 6, no. 4, pp. 477-487, August 2008 .

[3] N. Matsui, "Sensorless PM brushless DC motor drives," IEEE Trans. on Industrial Electronics, vol. 43, no. 2, pp. 300-308, 1996.

[4] K. Xin, Q. Zhan, and J. Luo, "A new simple sensorless control method for switched reluctance motor drives," KIEE J. Electr. Eng. Technol., vol. 1, no. 1, pp. 52-57, 2006.

[5] S. Ogasawara and H. Akagi, "An approach to position sensorless drive for brushless DC motors," IEEE Trans. on Industry Applications, vol. 27, no. 5, pp. 928-933, 1991.

[6] J. C. Moreira, "Indirect sensing for rotor flux position of permanent magnet AC motors operating over a wide speed range," IEEE Trans. on Industry Applications, vol. 32, no. 6, pp. 1394-1401, 1996.

[7] J. X. Shen, Z. Q. Zhu, and D. Howe, "Sensorless flux-weakening control of permanent-magnet brushless machines using third harmonic back EMF," IEEE Trans. on Industry Applications, vol. 40, no. 6, pp. 1629-1636, 2004.

[8] T. M. Jahns, R. C. Becerra, and M. Ehsani, "Integrated current regulation for a brushless ECM drive," IEEE Trans. on Power Electronics, vol. 6, no. 1, pp. 118-126, 1991.

[9] H. R. Andersen and J. K. Pedersen, "Sensorless ELBERFELD control of brushless DC motors for energy-optimized variable-speed household refrigerators," EPE Conf. Rec., vol. 1, pp. 314- 318, 1997.

[10] G. J. Su and J. W. Mckeever, "Low cost sensorless control of brushless DC motors with improved speed range," IEEE Trans. on Power Electronics, vol. 19, pp. 296-302, 2004.

[11] K. Iizuka, H. Uzuhashi, and M. Kano, "Microcomputer control for sensorless brushless motor," IEEE Trans. on Industry Applications, vol. 27, pp. 595-601, 1985.

[12] H. G. Yee, C. S. Hong, J. Y. Yoo, H. G. Jang, Y. D. Bae, and Y. S. Park, "Sensorless drive for interior permanent magnet brushless DC motors," Proc. of IEEE International Conf. on Electric Machines and Drives, 18-21, pp.TD1/3.1-3.3, 1997.

[13] Q. Jiang, C. Bi, and R. Huang, "A new phasedelay- free method to detect back EMF zerocrossing points for sensorless control of spindle motors," IEEE Trans. Magn., vol. 41, no. 7, pp. 2287-2294, 2005. 